\title{
A comparative study for different shielding material composition and beam geometry applied to PET facilities: simulated transmission curves
}

\author{
Gabriela Hoff, Paulo Roberto Costa*
}

\begin{abstract}
The aim of this work is to simulate transmission data for different beam geometry and material composition in order to evaluate the effect of these parameters on transmission curves. The simulations are focused on outgoing spectra for shielding barriers used in PET facilities. The behavior of the transmission was evaluated as a function of the shielding material composition and thickness using Geant4 Monte Carlo code, version $9.2 \mathrm{p}$ 03. The application was benchmarked for barited mortar and compared to The American Association of Physicists in Medicine (AAPM) data for lead. Their influence on the transmission curves as well the study of the influence of the shielding material composition and beam geometry on the outgoing spectra were performed. Characteristics of transmitted spectra, such as shape, average energy and Half-Value Layer (HVL), were also evaluated. The Geant4 toolkit benchmark for the energy resulting from the positron annihilation phenomena and its application in transmission curves description shown good agreement between data published by American Association on Physicists in Medicine task group 108 and experimental data published by Brasil. The transmission properties for different material compositions were also studied and have shown low dependency with the considered thicknesses. The broad and narrow beams configuration presented significant differences on the result. The fitting parameter for determining the transmission curves equations, according to Archer model is presented for different material. As conclusion were defined that beam geometry has significant influence and the composition has low influence on transmission curves for shielding design for the range of energy applied to PET.
\end{abstract}

Keywords PET, Transmission curves, Monte Carlo simulation.

\section{Estudo comparativo entre diferentes composições de materiais de blindagem e geometrias de feixe aplicadas a instalações para PET: curvas de transmissão simuladas}

Resumo O objetivo deste trabalho é simular dados de transmissão para feixes de diferentes geometria e composição de materiais, a fim de avaliar o efeito destes parâmetros em curvas de transmissão. As simulações estão focadas em espectros de saida para blindagem por barreiras utilizadas em instalações de PET. O comportamento da transmissão foi avaliado como uma função da composição do material de blindagem e de sua espessura, usando o código de Monte Carlo Geant4, versão 9.2 p 03. A aplicação foi validada para argamassa baritada e comparada com dados publicados pela Associação Americana de Físicos em Medicina (AAPM) para o chumbo. Foram realizadas avaliações da influência da geometria do feixe e da composição do material sobre os espectros de saída e sobre as curvas de transmissão. Características de transmissão dos espectros, tais como a forma, a energia média e a camada de semirredutora (HVL), também foram avaliadas. A ferramenta Geant4, para a energia resultante de fenômenos de aniquilação de pósitrons e sua aplicação na descrição de curvas de transmissão, mostrou boa concordância entre os dados publicados pelo grupo de trabalho 108 da Associação Americana de Físicos em Medicina e dados experimentais publicados no Brasil. As propriedades de transmissão para diferentes composições de materiais foram também estudadas e mostraram baixa dependência com as espessuras consideradas. A configuração de feixes largos e estreitos apresentaram diferenças significativas nos resultados. Os parâmetros de ajuste para a determinação das equações que representam as curvas de transmissão, de acordo com o modelo de Archer, são apresentados para diferentes materiais. Como conclusão, pode-se dizer que a geometria do feixe tem influência significativa e a composição tem pouca influência nas curvas de transmissão para projetos de blindagem para a faixa de energia aplicadas em PET.

Palavras-chave PET, Curvas de transmissão, Simulação por Monte Carlo.

*e-mail: pcosta@if.usp.br

Recebido: 28/08/2012 / Aceito: 14/12/2012 


\section{Introduction}

Since 1953 with the development of positron imaging device for clinical use, at Massachusetts General Hospital, the radiation safety for patients and for occupational workers has been considered an important part of this technique application (Cruzate and Discacciatti, 2008). In this technique, which uses positron annihilation radiation into the patient body, the energy absorption is low. Consequently, the dose rate for patients is reduced by a significant factor (Brinkley et al., 2009; Cruzate and Discacciatti, 2008). The published study by Brinkley et al. (2009) evaluated the influence of the scatter in the patient and had identified that the fraction of lower energies is significant compared to $511 \mathrm{keV}$ photons and can influence the effective attenuation of lead in clinical PET facilities. In order to find optimized shielding barriers, different authors have published information regarding the transmission curves (Demir and Keles, 2006; Elschot et al., 2010; Madsen et al., 2006). Many published papers have been used Monte Carlo toolkits to generate those data and to explore different possibilities for transmission curves (Brinkley et al., 2009; Cruzate and Discacciatti, 2008; Hoff et al., 2010; Madsen et al., 2006). The definition of these photon transmission curves of the available and regularly commercialized materials is important in order to determine the shielding thickness for introducing safe medical applications environments. The determination of the needed shielding thicknesses is important to guarantee the environmental adequacy for the occupational workers and to reduce cost of building PET facilities. Therefore, the objective of this work was to simulate the transmission $(\mathrm{T})$ and to calculate half - value layer (HVL) data based on shielding outgoing spectrum used on PET facilities (Hoff et al., 2010; Madsen et al., 2006; National..., 2005). In this paper, Geant 4 toolkit was used to evaluate the influence of the shielding material composition and beam geometry (evaluating narrow and broad beam configuration) on the transmission curves shapes and intensities. Fitting equation parameters were calculated, according to the model proposed by Archer et al. (1983), for broad beam configuration and barited mortar, lead, concrete, iron and steel shielding. The results present comparative data for narrow and broad beam configuration and the influence of different material compositions on transmission data and outgoing spectra. Spectrum characteristics, such as shape, average energy and HVL, were also evaluated.

\section{Materials and Methods}

This work was developed in four different steps: (i) benchmark of the toolkit for the application, (ii) study of the influence of the shielding composition and beam geometry on the transmission curves, (iii) study of the influence of the shielding material composition and beam geometry on the outgoing spectra, and (iv) generation of fitting parameter for determining the transmission curves equations. The Geant 4 version 9.2 p 03 simulation toolkit (Agostinelli et al., 2003; Allison et al., 2006) was used to achieve these objectives. The simulated universe was described as a sphere with a diameter of $20 \mathrm{~m}$ composed by dry air according to the International Commission on Radiation Units and Measurements (International..., 1989) in the descriptions presented in report 44 . The geometry considers one punctual source irradiating monoenergetic photons of $511 \mathrm{keV}$ homogeneously into a solid angle which covers the irradiation area defined as narrow or broad beam. It was simulated an entrance beam area with $(1 \times 1) \mathrm{cm}^{2}$ for narrow beam and with $(70 \times 70) \mathrm{cm}^{2}$ for broad beam in order to explore these two different beam configurations. The source to shielding wall entrance distance was $60 \mathrm{~cm}$. Two sensitive volumes were simulated: one in front of the shielding wall (58 $\mathrm{cm}$ far from the source) and other behind it (placed $62 \mathrm{~cm}$ plus the higher shielding thickness studied for a specific material). The sensitive volumes were considered as spheres of air with $1 \mathrm{~cm}$ of radius and they were defined estimate the absorbed energy and photon flux (from energies $1 \mathrm{keV}$ up to $511 \mathrm{keV}$ ), with and without the shielding wall.

Different materials are reported in the literature as possible to be used for shielding photon beams. Some of them are lead, concrete, steel, and bismuth borate glasses (Demir and Keles, 2006; Elschot et al., 2010; Madsen et al., 2006; Singh et al., 2002). In the present work, the shielding evaluated were made of pure lead, concrete, described according Simpkin $(1989,1995)$ and International Commission on Radiation Units and Measurements (International..., 1989) report 44; iron alloy (named steel) composed by $1 \%$ of carbon and $99 \%$ of iron, pure iron, and four different barited mortar with chemical compositions experimentally determined using $\mathrm{x}$-ray fluorescence technique. These mortars were selected by four traditional Brazilian providers. The mass densities of the mortars were also determined according Brazilian regulation. Table 1 shows the chemical composition of the materials studied in the present work.

The transmission ( $\mathrm{T}$ ) data were determined using the absorbed energy accounted by the sensitive volume placed behind the shielding wall. Each transmission data point was calculated using the result of two simulations: one colleting the absorbed energy by the sensitive volume with the shielding barrier $\left(\mathrm{E}_{\mathrm{abi}}\right)$ and other collecting the absorbed energy by the sensitive volume without the shielding barrier $\left(\mathrm{E}_{\mathrm{abo}}\right)$. This approximation in the calculation can be used because 
according the National Institute of Standard and Technology (Hubbell and Seltzer, 1996) the imparted energy is equivalent to the absorbed energy in the air sensitive volume. So, the transmission was calculated considering the ratio between the absorbed energy with and without the shielding barrier according to Equation 1. The theory of error propagation for independent variables was used to calculate the error of the transmission data caused by the fluctuation in the simulated values.

$T=\frac{E_{a b i}}{E_{a b o}}$

A group of quantitative statistical tests were chosen in order to evaluate the differences observed on the results of the present work. These quantitative statistical evaluations were performed by using Wald-Wolfowitz, Anderson Darling, Chi-Square and Kolmogorov-Smirnov tests on the comparative transmission data. To evaluate the outgoing spectra from the shielding wall it was used Pearson Chi-Square test and Kolmogorov-Smirnov test. The level of significance of the tests described in the following sections is 0.001 , it means that the null hypothesis is rejected whenever the $\mathrm{p}$-value resulting from the test statistic is smaller than 0.001 . The $\mathrm{R}$ statistical toolkit was used to calculate these values, with exception to the Chi-square test, which was performed by generic spreadsheet. In this case, the p-value was calculated from "chidist" function. The combined evaluation of the statistical results was used to define the similarities and differences. This combined evaluation considered good agreement for the group of data that pass at least on 3 of the goodness of fit tests (for the transmission evaluation) and for both testes (for spectra evaluation).

The benchmark was performed by using the transmission data for lead published by Madsen et al. (2006) at American Association on Physicists in Medicine Task Group 108 and experimental data published by Brasil (2009) and Hoff et al. (2010). The study of the influence of shielding composition and beam geometry on the transmission curves and outgoing spectra were performed for lead, concrete, steel and iron. The outgoing spectra from the shielding

Table 1. Chemical composition of the simulated material.

\begin{tabular}{|c|c|c|c|c|c|c|}
\hline \multirow{2}{*}{$\begin{array}{l}\text { Chemical } \\
\text { Element }\end{array}$} & \multirow[b]{2}{*}{ BM1 } & \multirow[b]{2}{*}{ BM2 } & \multirow[b]{2}{*}{ BM3 } & \multirow[b]{2}{*}{ BM4 } & \multicolumn{2}{|c|}{ Concrete } \\
\hline & & & & & Simpkin & ICRU 44 \\
\hline $\mathrm{H}$ & - & - & - & - & 0.00560 & 0.02210 \\
\hline $\mathrm{C}$ & - & - & - & - & - & 0.00248 \\
\hline $\mathrm{Ba}$ & 0.28948 & 0.37000 & 0.21022 & 0.36493 & - & - \\
\hline $\mathrm{Ca}$ & 0.18330 & 0.11100 & 0.24025 & 0.15953 & 0.08260 & 0.04295 \\
\hline $\mathrm{O}$ & 0.18030 & 0.03000 & 0.16017 & 0.17947 & 0.49830 & 0.57493 \\
\hline $\mathrm{Si}$ & 0.14524 & 0.01580 & 0.04905 & 0.07977 & 0.31580 & 0.30463 \\
\hline $\mathrm{S}$ & 0.06411 & 0.17300 & 0.04104 & 0.07977 & 0.00120 & - \\
\hline $\mathrm{Al}$ & 0.02935 & - & 0.01331 & 0.02204 & 0.04560 & 0.01995 \\
\hline $\mathrm{Fe}$ & 0.02404 & 0.03200 & 0.16017 & 0.03889 & 0.01220 & 0.00644 \\
\hline $\mathrm{Mg}$ & 0.01482 & 0.00340 & 0.02513 & 0.01296 & 0.00240 & 0.00127 \\
\hline $\mathrm{P}$ & 0.00661 & 0.00890 & 0.01702 & 0.00957 & - & - \\
\hline $\mathrm{K}$ & 0.01192 & 0.00040 & 0.00181 & 0.00518 & 0.01920 & 0.01005 \\
\hline $\mathrm{Ti}$ & 0.00351 & 0.00290 & 0.00681 & 0.00309 & - & - \\
\hline $\mathrm{Mn}$ & 0.00140 & 0.00100 & 0.00350 & 0.00219 & - & - \\
\hline $\mathrm{Na}$ & 0.00160 & 0.00130 & 0.00100 & 0.00399 & 0.01710 & 0.01521 \\
\hline $\mathrm{Sr}$ & 0.00065 & 0.00100 & 0.00200 & 0.00105 & - & - \\
\hline $\mathrm{Cl}$ & 0.00030 & - & 0.00020 & 0.00018 & - & - \\
\hline $\mathrm{Zn}$ & 0.00010 & - & 0.00010 & 0.00010 & - & - \\
\hline $\mathrm{Zr}$ & 0.00009 & 0.00013 & 0.00038 & - & - & - \\
\hline $\mathrm{Rb}$ & 0.00005 & - & - & - & - & - \\
\hline $\mathrm{Ni}$ & - & 0.00017 & 0.00016 & 0.00020 & - & - \\
\hline $\mathrm{Nb}$ & 0.00005 & - & 0.00017 & 0.00006 & - & - \\
\hline $\mathrm{Ce}$ & - & - & 0.00300 & - & - & - \\
\hline $\mathrm{Cr}$ & - & - & 0.00041 & - & - & - \\
\hline $\mathrm{Y}$ & - & - & 0.00003 & 0.00003 & - & - \\
\hline $\mathrm{Cu}$ & - & - & - & 0.00012 & - & - \\
\hline $\mathrm{H}_{2} \mathrm{O}$ & 0.04307 & 0.24900 & 0.06407 & 3.68900 & - & - \\
\hline Density $\left(\mathrm{g} / \mathrm{cm}^{3}\right)$ & 2.15 & 2.01 & 2.68 & 2.21 & 2.35 & 2.30 \\
\hline
\end{tabular}


barrier are presented in flux probability. This quantity represents the number of photons crossing the sensitive volume at a specific energy divided by the number of photons emitted from the source. They were evaluated considering its average energy, the half - value layer (HVL) and the shape of the photon flux probability as function of the energy. The fitting parameters for the transmission curves were calculated for broad beam considering lead, iron, steel and the different compositions of barited mortar and concrete. The calculation of these parameters was based on method published by Archer et al. (1983), and was performed using an Origin 8.0 (Microcal, inc.) fitting routine. The Equation 2 presents the formulation for calculating the shielding thickness (x) using the fitting parameters $\alpha$, $\beta$ and $\gamma$ for the considered material. In this equation, $\mathrm{K}_{0}$ is the air kerma at the detector position without the shielding and $\mathrm{K}$ is the air kerma in the same position after the photons were transmitted by the shielding.

$$
x=\frac{\operatorname{Ln}\left[\frac{\left(\frac{K_{0}}{K}\right)^{\gamma}+\frac{\beta}{\alpha}}{1+\frac{\beta}{\alpha}}\right]}{\alpha \gamma}
$$

\section{Results}

The results are presented in four steps: (a) benchmark of the simulation, (b) study considering the influence of different composition and beam geometry on transmission curves, (c) fitting equation parameters for the studied materials, and (d) study of beam geometry on outgoing spectra from shielding barrier.

\section{The benchmark of the simulation}

Figure 1 presents transmission data for lead considering incident flux of $511 \mathrm{keV}$ photons, as published by Madsen et al. (2006) at AAPM Task Group 108. In the same figure is represented the simulation data obtained by Geant 4 toolkit.

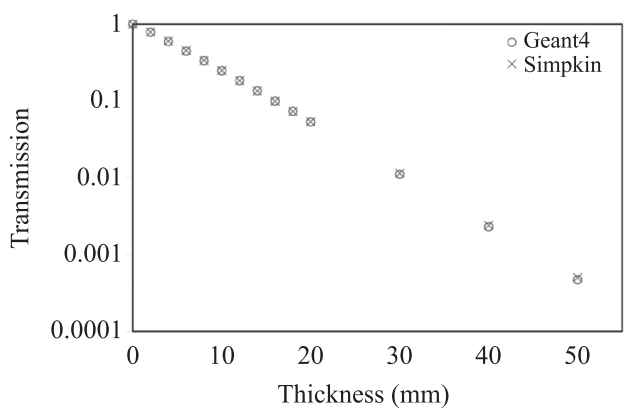

Figure 1. Transmission data simulated for lead published by AAPM 108 (Madsen et al., 2006) and simulated using Geant4 toolkit in this work.
Figure 2 presents the experimental and simulated data for different shielding thickness for the four barited mortar compositions studied.

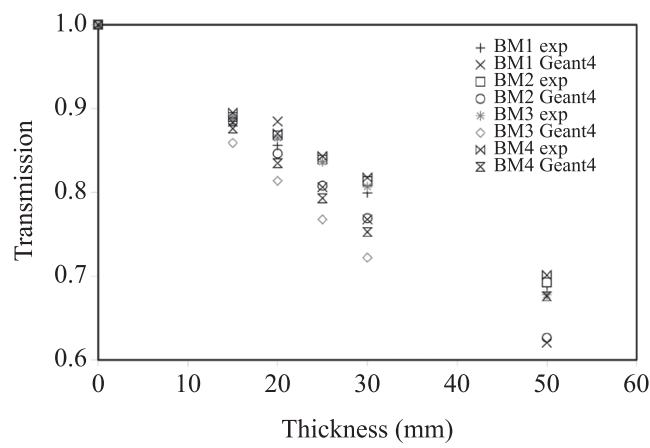

Figure 2. Transmission data simulated for barited mortar in this work and published experimental data (Brasil, 2009).

(a)
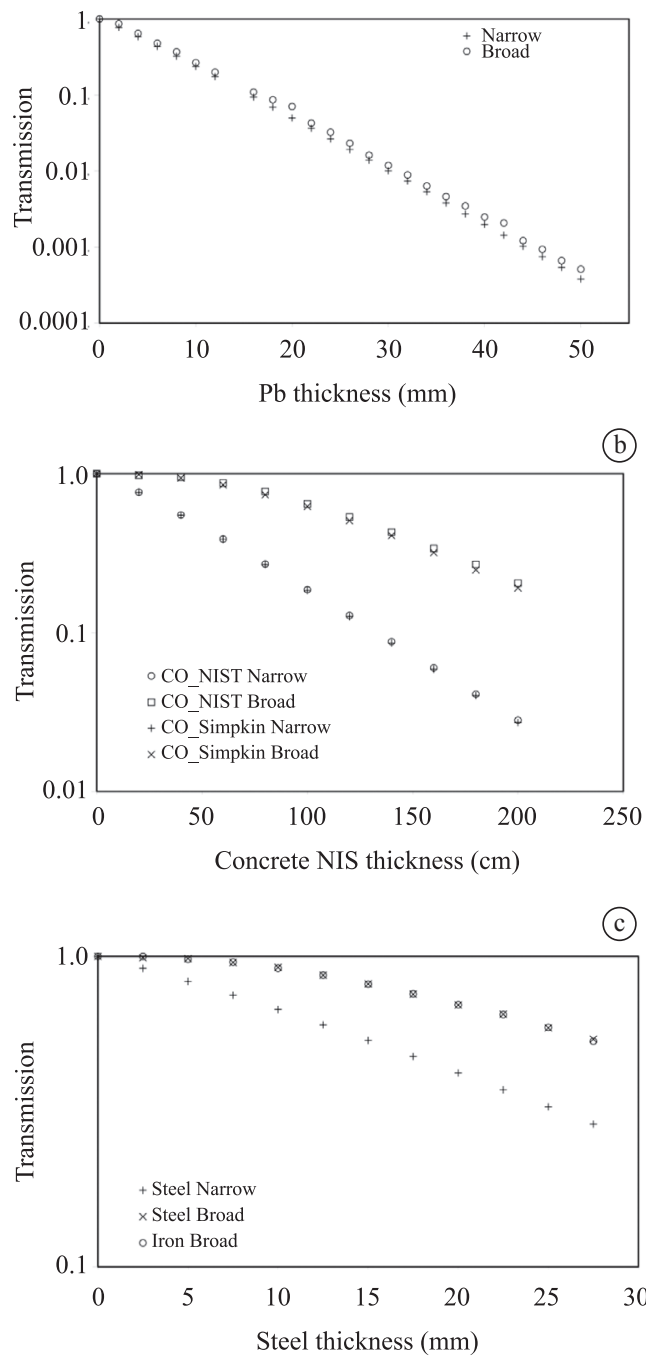

Figure 3. Transmission data simulated for the geometries and materials studied (a) lead, (b) concrete and (c) steel and iron. 


\section{Influence of different composition and beam geometry on transmission curves}

The transmission data for different geometry configuration are presented in Figure 3.

\section{Fitting parameters}

According Madsen et al. (2006) the broad beam geometry is the one recommended as a good representation for mimic a PET beam application. Table 2 presents the fitting parameters for the Equation 2 for all studied material according to the simulated broad beam geometry.

\section{The outgoing spectra characterization}

The graphs in Figures 4a-b, 5a-b, 6a-b and 7a-b present average energy and the HVL of the outgoing spectra for the different material and beam configuration and thickness studied. The graphs presented in Figures 4c-d, $5 \mathrm{c}-\mathrm{d}, 6 \mathrm{c}-\mathrm{d}$ and $7 \mathrm{c}-\mathrm{d}$ show the spectra for the different beam geometry and material composition for the thinner and thicker shielding wall simulated. The spectra graphs were rescaled for make possible to verify the observed differences. So the maximum flux probability is described in the legend of Figure $4 c, d$, $5 \mathrm{c}-\mathrm{d}, 6 \mathrm{c}-\mathrm{d}$ and $7 \mathrm{c}-\mathrm{d}$ for the energy of $511 \mathrm{keV}$.

\section{Discussion}

There are many sources for experimental data (Almeida Junior, 2005; Brasil, 2009; Hoff et al., 2009; Singh et al., 2002). The problem in comparing these

(a)
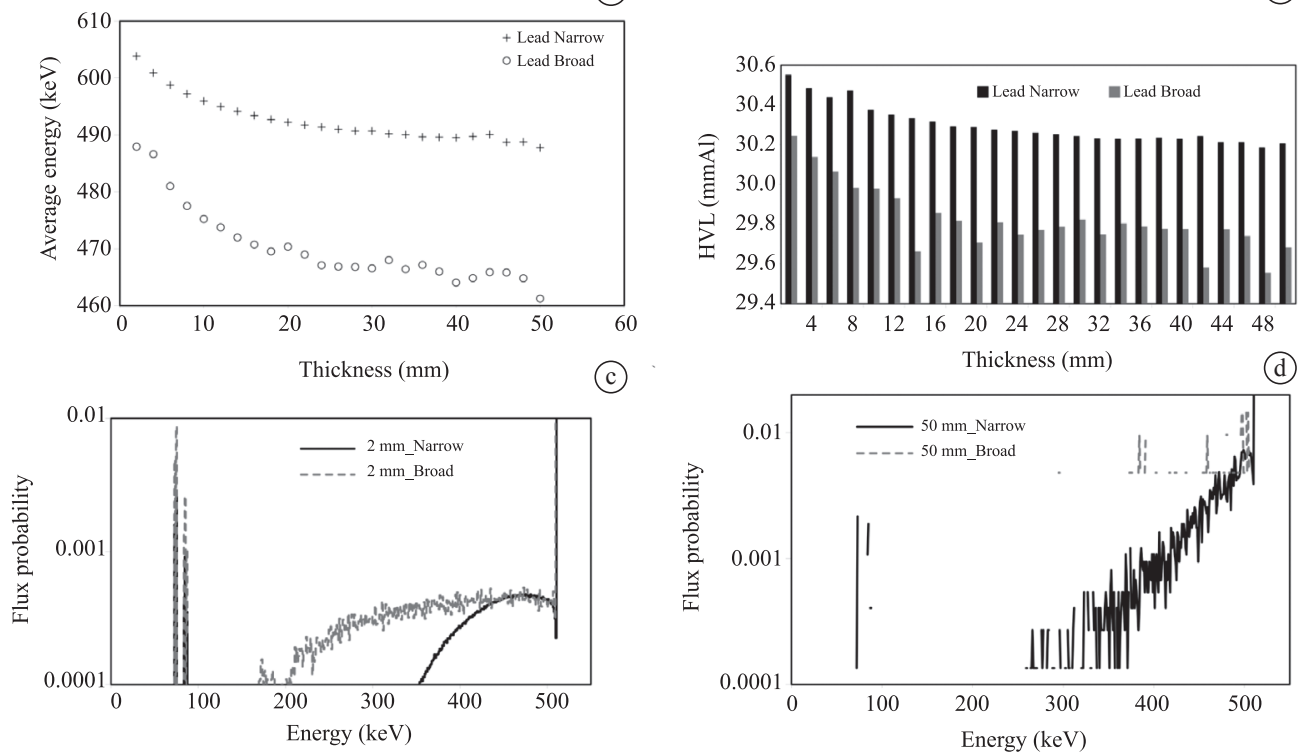

Figure 4. a) Average energy and b) half value layer for different shielding thickness evaluated for lead as shielding material. Spectra study for lead presented as flux probability as function of the energy: c) $2 \mathrm{~mm}$ (maximum flux probability for narrow beam is 0.9362 and broad beam is 0.6749 ) and d) $50 \mathrm{~mm}$ comparing narrow and broad beam (maximum flux probability for narrow beam is 0.6235 and broad beam is 0.4135 ).

Table 2. Fit equation parameters for broad beam configuration and the studied materials.

Fitting coeficientes

\begin{tabular}{ccccc} 
Material & Alfa $(\alpha)$ & Beta $(\beta)$ & Gamma $(\gamma)$ & $x_{\text {red }}^{2}$ \\
\hline BM1 & 0.80328 & -0.78784 & $-6.61245 .10^{-4}$ & 0.00401 \\
BM2 & 0.61052 & -0.6014 & 0.00386 & 0.00031 \\
BM3 & 0.40587 & -0.39483 & 0.00709 & 0.00030 \\
BM4 & 0.40587 & -0.39833 & 0.00911 & 0.00054 \\
Lead & 0.14997 & -0.10828 & 6.71255 & 0.00043 \\
CO (Simpkin) & 0.98931 & -0.98667 & 0.01057 & 0.00195 \\
CO (NIST) & 0.98312 & -0.98078 & 0.01123 & 0.00204 \\
Iron & 0.61027 & -0.59321 & 0.03516 & 0.00251 \\
Steel & 0.03879 & -0.0358 & 5.76223 & 0.00003 \\
\hline
\end{tabular}


data on simulation procedures is to get all specific information from geometry, used spectra and material composition. In the present work, the benchmark of the simulation considering experimental data collection was based on published data (Brasil, 2009; Hoff et al., 2010) which provided the information needed to build a simulation in the same conditions of the experiment. The discussions are presented in the same structure then results.

\section{The benchmark of the simulation}

Figure 1 presents a good visual agreement between the simulated data in this work and the data published by Madsen et al. (2006). The statistical tests applied to these data in order to evaluate the statistical significance of the agreement considering one standard deviation. The Wald-Wolfowitz test confirms the randomness of the Geant 4 simulation according Madsen et al. (2006) reference data (test value 3.408 and p-value $<0.001)$. It means that the simulation does not present systematics differences according the tendency curve of the reference data. The Kolmogorov-Smirnov (test value 0.071 and $p$-value 1.000), Anderson-Darling (test value -1.335 and $p$-value 0.717 ) and Chi-Square (test value 16.564 and p-value 0.220 ) present $\mathrm{p}$-values confirmed the goodness of fit to a significance level of 0.001 , what shows that Geant4 simulation has same curve shape than the reference data. The ChiSquare test was performed considering the error associated to the Geant4 simulation. The variations/ errors on reference data were not adopted because this information was not available.

Figure 2 presents a similar tendency between experimental and simulated data, but the experimental data is always above the simulated one. The randomness test was used to evaluate the agreement on data comparing the different composition of barited mortar. The values presented by Wald-Wolfowitz test (BM1 value test 0.527 and $p$-value 0.299 , BM2 value test 0.782 and $p$-value $0.217, \mathrm{BM} 3$ value test 1.740 and p-value 0.041 , BM4 value test 1.5780 .057 ) confirm the significance of the systematic difference between the Geant 4 simulation and the experimental data for barited mortar. These differences can be explained by subtle changes in the barited mortar composition or by the small differences on time determination to correct the experimental data or beam geometry description between experimental and simulated data. The Kolmogorov-Smirnov (presents test values of 0.167 and p-values of 1.000 to BM1 and BM2, and test values of 0.333 for p-values of 0.893 to BM3 and BM4), Anderson-Darling (showing test values between -1.289 and -0.517 and $p$-values between 0.706 and 0.736 ) and Chi-Square p-values (always superior to 0.736 )

(a)
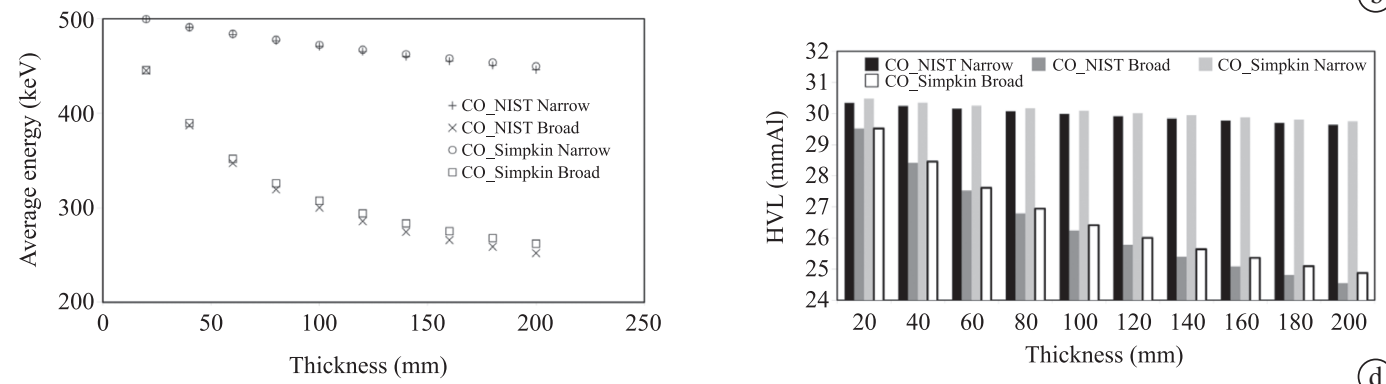

(c)
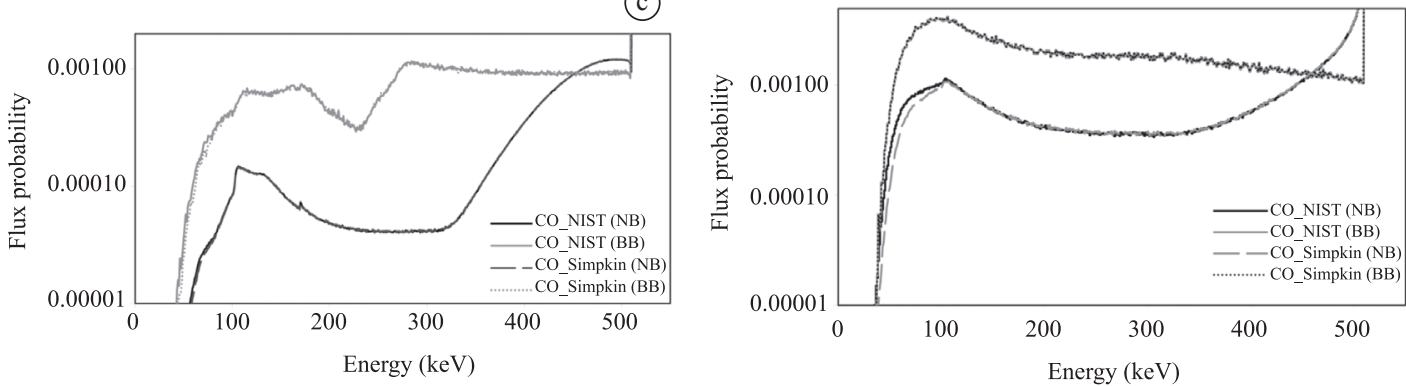

Figure 5. a) Average energy and b) half - value layer for different shielding thickness evaluated, considering the NIST and the Simpkin concrete composition. Spectra study for different concrete compositions studied presented as flux probability as function of the energy comparing narrow and broad beam configuration for c) $20 \mathrm{~mm}$ (maximum flux probability for CO-NIST narrow beam is 0.8745 and broad beam is 0.0874 , and CO-NIST narrow beam is 0.8744 and broad beam is 0.0423 ) and for d) 200 mm (maximum flux probability for CO-NIST narrow beam is 0.6201 and broad beam is 0.0052 , and CO-NIST narrow beam is 0.6261 and broad beam is 0.0052 ). 
confirmed the good agreement between the Geant 4 simulation and the experimental data. The Chi-Square test was performed considering the error associated to the Geant 4 simulation and the variation presented by each experimental data points $(10 \%)$.

\section{Influence of different composition and beam geometry on transmission curves}

The transmission data for different geometry presents small differences between broad and narrow beams geometries for lead (Figure 3a). For both compositions of concrete (Figure 3b) and steel (Figure 3c) the differences between broad and narrow geometries were significant, including a change on shape that can be seen on the different model for the presented fitting curves.

The statistical evaluation of the effect of the beam geometry on transmission data shows significant differences between the curves simulated for the different beam geometries with the exception for lead. According Chi-Squares (with p-values $<0.001$ with exception for lead that presented p-value of 0.005) and Anderson-Draling tests (that presents test values between 3.610 and 3.891 with p-values between 0.009 and 0.011 with exception to lead presenting test value of -1.225 and p-value 0.689 ) the geometry can influence significantly the transmission curves, with the exception for lead. The Kolmogorov-Smirnov test presented bordering results. The Wald-Wolfowitz test results, with p-values between 0.242 and 0.316 to all materials, show the non-randomness of the compared distributions. It means the systematic differences can be found between the transmissions curves caused by the beam geometry.

The statistical evaluation of the material composition effect on transmission data (with exception for steel and iron) showed a small influence.

Data compared presented p-values above 0.001 (between 0.132 and 0.256 ) for Wald-Wolfowitz test, confirming the significance of the systematic differences between the simulated data for the different shielding material composition compared, with exception for concrete that presents p-values of 0.002 to narrow beam geometry and 0.015 to broad beam geometry. It means that the material composition can change the intensity for the transmission data. However the Chi-Square test results shown that these differences are not significant when the errors from the simulations are considered.

The influence of shielding material composition on transmission data did not show significant differences for the incoming energy of $511 \mathrm{keV}$.

The literature presents published works using different kind of barited mortar and different techniques

(a)
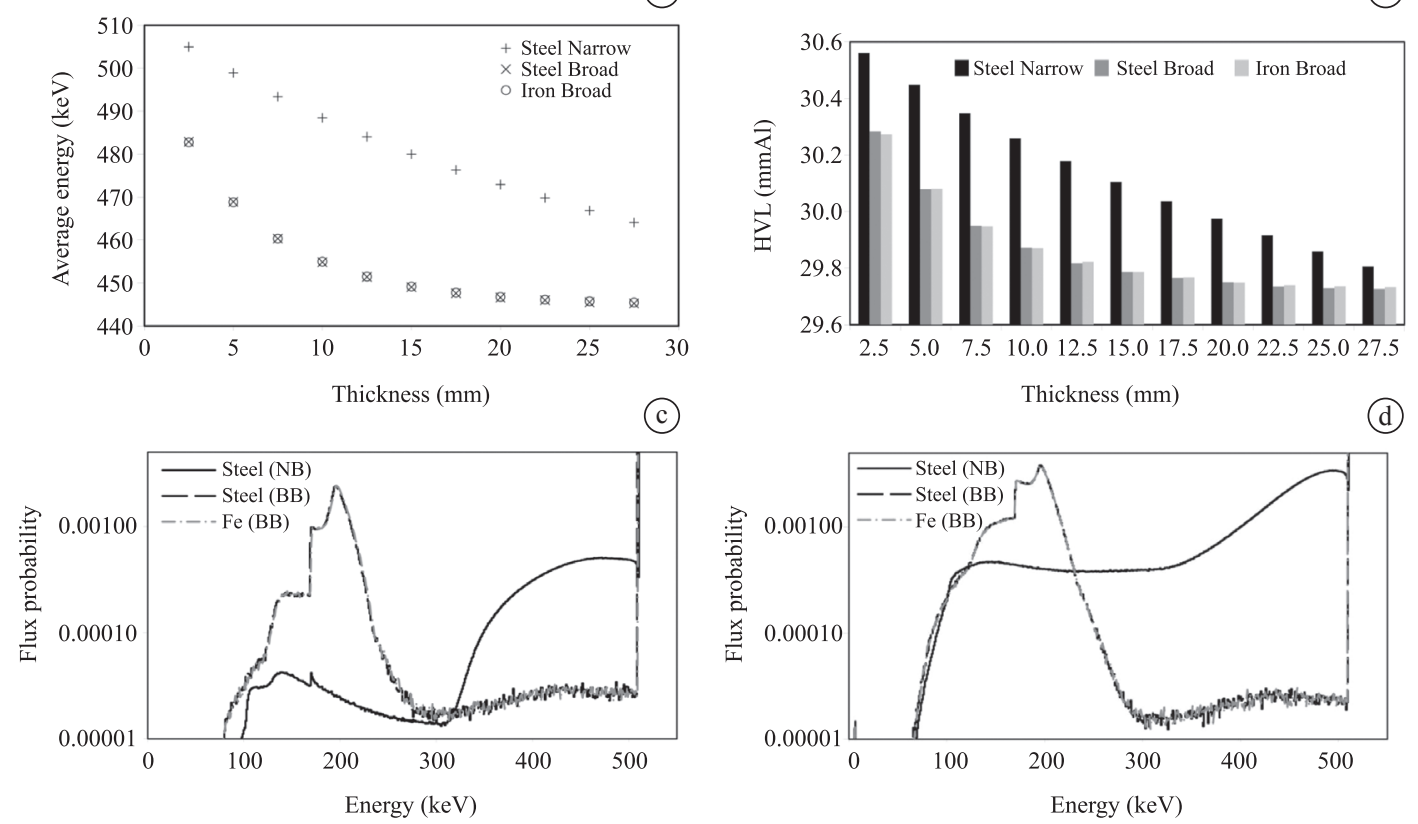

Figure 6. a) Average energy and b) half - value layer for different shielding thickness evaluated, considering Steel and Iron as shielding material. Spectra study for Steel and Iron presented as flux probability as function of the energy comparing narrow and broad beam configurations for c) $2.5 \mathrm{~mm}$ (maximum flux probability for Steel narrow beam is 0.9329 , Steel broad beam is 0.0581 and Iron broad beam is 0.0581 ) and for d) $27.5 \mathrm{~mm}$ (maximum flux probability for Steel narrow beam is 0.5974 , Steel broad beam is 0.0511 and Iron broad beam is 0.0511 ). 
to determine its elemental composition and density (Almeida Junior, 2005; Brasil, 2009; Hoff et al., 2009). The densities are in the range from 1.98 to $2.68 \mathrm{~g} / \mathrm{cm}^{3}$, but it is strongly dependent from the quantity of barited and high atomic number elements. For barited mortar the results presented in the present work do not demonstrated significant influence of its material composition on transmission curves. It is important to note that the results shown a tendency to increase the transmission values when the density of the barited mortar decreases, as was expected and reported in the published data (Almeida Junior, 2005; Brasil, 2009; Hoff et al., 2009).

\section{Fitting parameters}

The presented parameters can be used to calculate shielding thickness for the different evaluated materials. Because systematic errors indicated by Wald-Wolfowitz test, that are the reflection of systematic differences on the transmission intensity (even it is smaller than the error in the simulation), it is recommendable that one who will use these equations choose the one that match to the considered material composition. In case the composition of the material is unknown, it is recommendable to select the one which presents the larger thickness.

\section{The outgoing spectra characterization}

The Figure 4 shows the average energy and HVL for lead. The average energy is lower for all data points for broad beam configuration as well the HVL. It happens because of the scatter radiation contribution for larger irradiation areas. The same behavior can be observed for the other material (Figures 5 and 6). Figure $4 \mathrm{a}, \mathrm{b}$ presented a difference of approximately $10 \mathrm{keV}$ for narrow beam configuration and $30 \mathrm{keV}$ for broad beam configuration between $2 \mathrm{~mm}$ and $50 \mathrm{~mm}$ of lead. For the same thickness of shielding material, the HVL decreased $0.3 \mathrm{~mm}$ and $0.7 \mathrm{~mm}$ of aluminum for narrow and broad beam configuration, respectively.

Figure $4 \mathrm{c}$, d show the flux probability for $2 \mathrm{~mm}$ and $50 \mathrm{~mm}$ of lead. The statistical analyses for all studied cases presented significant differences calculated by Pearson Chi-Square test and significant systematic differences between the compared spectra by using Wald-Wolfowitz test. Besides that, the transmission curves were not significant affected by these changes.

Figure 5 shows the average energy and HVL for concrete. The average energy is lower for all data points for broad beam configuration as well the HVL. There were no significant difference between the HVL for different material composition and same beam geometry. Figure 5a shows a difference of approximately $50 \mathrm{keV}$ for narrow beam configuration and $200 \mathrm{keV}$ for broad beam configuration between $10 \mathrm{~mm}$ and $200 \mathrm{~mm}$ of both concrete compositions studied (Figure 5a, b). For the same thickness of shielding material, the HVL decreased about $1 \mathrm{~mm}$ and $5 \mathrm{~mm}$ of aluminum for narrow and broad beam configuration, respectively.

Figure $5 \mathrm{c}$, d show the flux probability for $10 \mathrm{~mm}$ and $200 \mathrm{~mm}$ of concrete. The statistical analyses for all studied cases presented significant differences calculated by Pearson Chi-Square test and significant systematic differences between the compared spectra by using Wald-Wolfowitz test when different beam geometry are compared. It means that the spectra shape is significantly influenced by the beam geometry for PET application. The statistical analyses show no significant differences between the concrete compositions in the studied thickness. It means that the concrete compositions evaluated do not have significant effect the outgoing spectra.

Figure $6 \mathrm{a}, \mathrm{b}$ show the average energy and HVL for steel and iron. There were no significant difference between the HVL for different material composition and same beam geometry and significant differences between broad beam and narrow beam configuration. Figure $6 \mathrm{c}, \mathrm{d}$ present a difference of approximately $35 \mathrm{keV}$ for narrow beam configuration and $46 \mathrm{keV}$ for broad beam configuration between $2.5 \mathrm{~mm}$ and $27.5 \mathrm{~mm}$ of steel and iron. To the same thickness of shielding material, the HVL decreased about $0.6 \mathrm{~mm}$ and $0.7 \mathrm{~mm}$ of aluminum for narrow and broad beam configuration respectively.

Figure $6 \mathrm{c}$, d present flux probability for $2.5 \mathrm{~mm}$ and $27.5 \mathrm{~mm}$ of steel and iron. The statistical analyses for all studied cases presented significant differences calculated by Pearson Chi-Square test and significant systematic differences between the compared spectra by using Wald-Wolfowitz test when different beam geometry are compared. It means that the spectra shape is significantly influenced by the beam geometry for PET application. When steel and iron are compared showing no significant differences for the thickness studied, which means that for the studied compositions there are not significant influence on the outgoing spectra.

Figure 7 shows the average energy and HVL for the different barited mortar studied. There was no significant difference between the HVL for different barite mortar (Figures 7a, b). Figures 7c, d present a difference of approximately $75 \mathrm{keV}$ for the different composition and about $3 \mathrm{~mm} \mathrm{Al}$ from 15 up to $400 \mathrm{~mm}$ of barited mortar. The barited mortar BM3 presented the lower average energy and HVL values. 

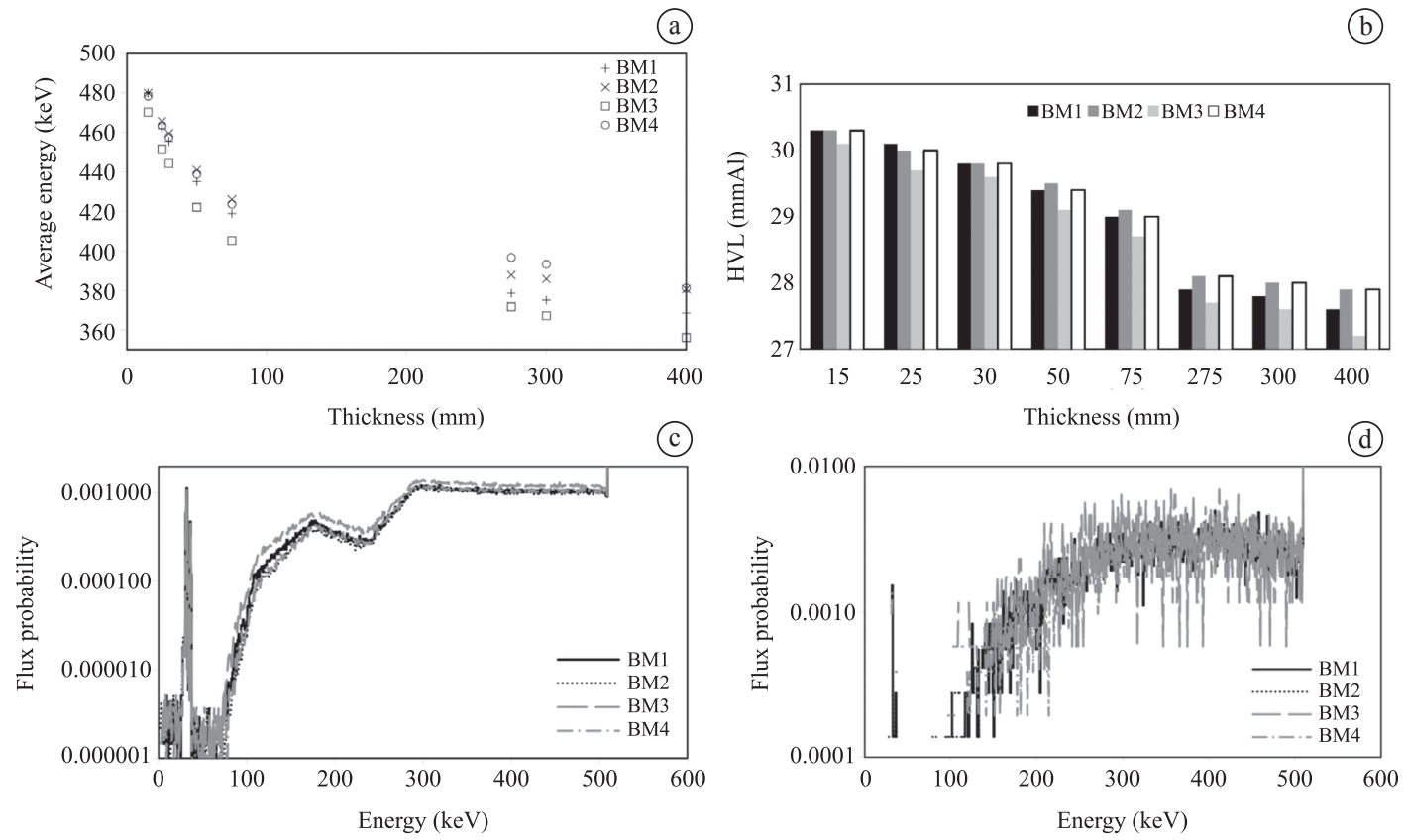

Figure 7. a) Average energy and b) half - value layer for different shielding thickness evaluated, considering barited mortar as shielding material. Spectra study for different composition of barited mortar presented as flux probability as function of the energy comparing narrow and broad beam configurations for c) $25 \mathrm{~mm}$ (maximum flux probability for BM1 is 0.5356 , BM2 is 0.5486 , BM3 is 0.4909 and BM4 is 0.5375 ) and for d) $400 \mathrm{~mm}$ (maximum flux probability for BM1 is 0.0812 , BM2 is 0.0812 , BM3 is 0.0572 and BM4 is 0.1009 ).

It is in agreement with the material characterization because is the BM3 the one that has higher density. The barited mortar BM1 and BM4 presented similar results for HVL and energy. These materials have closer values for density, among the evaluated barited mortar compositions.

Figure $7 \mathrm{c}, \mathrm{d}$ show the flux probability for $25 \mathrm{~mm}$ and $400 \mathrm{~mm}$ of different composition of barited mortar. The statistical analyses for all studied cases they presented no significant differences calculated by Pearson Chi-Square test. The Wald-Wolfowitz test presented this data is randomly distributed considering the different compositions and thickness of the studied material. It means that for this material the spectra shape was not significantly affected by the barited mortar studied compositions. The BM3 was the one that presented larger differences on flux probability when compared to other compositions for all studied thickness.

In the last 10 years, several papers discussed about the applied radiological protection in PET facilities (Cruzate and Discacciatti, 2008; Demir and Keles, 2006; Elschot et al., 2010; Hoff et al., 2010). These papers evaluated different possibilities to optimize the protection by investigating different material compositions used as shielding, the influence of self-absorption on PET, or sharing experimental data collected in PET facilities. The present work brings new information about barited mortar used as shielding for PET. It shows that changes on beam geometry can significant influence the transmission curves and changes on composition, for the same material, are not as significant as the geometry by influence the transmission curves.

\section{Conclusion}

This work described the evaluation of transmission curves applied to PET shielding design, based on simulated data. The Geant 4 toolkit was used and its benchmarking confirmed good agreement with published data by Madsen et al. (2006) at AAPM 108 task group and experimental data published by Brasil (2009).

The comparison between broad and narrow beam configuration presented statistical differences showing the changes in transmission data as well in outgoing spectra. In this work, all studied material (excepting lead) presented statistical significance differences between the broad and narrow beam. Therefore, considering the particularities of the PET technique, it is recommended that transmission studies for this application must use broad beam geometry. Broad beam simulated configuration results in larger errors in the evaluation compared to narrow beam configuration, because of that the broad beam configuration, using 
Monte Carlo codes, requires larger running times in order to get acceptable statistical results.

No significant differences were observed when different compositions of the same shielding material were compared. An exception of this result is the comparison between iron and steel. However the barited mortar data presented a significant difference between their transmission curves (observed in the Wald-Wolfowitz test). This result indicates its possible influence on the intensity of the transmission data. The observed tendency shows an increase on transmission data with the decrease in density for barited mortar.

Other expected behavior observed in the spectra evaluation was that the number of photons with the energy of $511 \mathrm{keV}$ decreases when the numbers of photons with lower energy increases. The interesting observation was that most significant energy that increases in number of photons, as well as fluence, was the $510 \mathrm{keV}$ and the photons with this energy increases most significantly that the other energies as function of the shielding thickness. It is caused by the increase on scatter photons considering the sensitive volume and it agreement to the decrease in mean energy and HVL data for broad beam configuration. The decreasing on total munber of photons collected by sensitive volume, because of the enlargement of the irradiation area results, resulting in high statistical fluctuations on spectra. For the spectra evaluated, the broad beam geometry always presented low mean energy and HVL than the narrow beam geometry. For broad beam geometry the outgoing energy from the shielding wall presented lower energies photons, specially with $511 \mathrm{keV}$, when compared to narrow beam geometry.

This work presents a group of fitting parameters that can be used to calculate the shielding thickness for PET application for different material: four different barited mortar and concrete compositions, lead, iron and steel. These fitting parameters were calculated based on broad beam geometry. Even the Chi-Square test showing no statistical significance in the statistical differences pointed by Wald-Wolfowitz test, it is recommendable that one who will use these equations chooses the one that matches the material composition. In case one does not know the material composition of the shielding, it is recommended to select the one that presents the larger thickness.

\section{Acknowledgements}

The authors thanks the Conselho Nacional de Desenvolvimento Científico e Tecnológico - CNPq (process 312029/2009-8), the Fundação de Amparo à Pesquisa do Estado de São Paulo - FAPESP (process 2010/12237-7) and the Coordenação de Aperfeiçoamento de Pessoal de Nivel Superior - CAPES (process BEX 6460/10-0) for the partial support to this work. This research project is part of the INCT project: Metrologia das Radiações Ionizantes na Medicina.

\section{References}

Agostinelli S, Allison J, Amako K, Apostolakis J, Araujo H, Arce P, Asai M, Axen D, Banerjee S, Barrand G, Behner F, Bellagamba L, Boudreau J, Broglia L, Brunengo A, Burkhardt H, Chauvie S, Chuma J, Chytracek R, Cooperman G, Cosmo G, Degtyarenko P, Dell'Acqua A, Depaola G, Dietrich D, Enami R, Feliciello A, Ferguson C, Fesefeldt H, Folger G, Foppiano F, Forti A, Garelli S, Giani S, Giannitrapani R, Gibin D, Gómez Cadenas JJ, González I, Gracia Abril G, Greeniaus G, Greiner W, Grichine V, Grossheim A, Guatelli S, Gumplinger P, Hamatsu R, Hashimoto K, Hasui H, Heikkinen A, Howard A, Ivanchenko V, Johnson A, Jones FW, Kallenbach J, Kanaya N, Kawabata M, Kawabata Y, Kawaguti M, Kelner S, Kent P, Kimura A, Kodama T, Kokoulin R, Kossov M, Kurashige H, Lamanna E, Lampén T, Lara V, Lefebure V, Lei F, Liendl M, Lockman W, Longo F, Magni S, Maire M, Medernach E, Minamimoto K, Mora de Freitas P, Morita Y, Murakami K, Nagamatu M, Nartallo R, Nieminen P, Nishimura T, Ohtsubo K, Okamura M, O’Neale S, Oohata Y, Paech K, Perl J, Pfeiffer A, Pia MG, Ranjard F, Rybin A, Sadilov S, Di Salvo E, Santin G, Sasaki T, Savvas N, Sawada Y, Scherer S, Sei S, Sirotenko V, Smith D, Starkov N, Stoecker H, Sulkimo J, Takahata M, Tanaka S, Tcherniaev E, Safai Tehrani E, Tropeano M, Truscott P, UnoH, Urban L, Urban P, Verderi M, Walkden A, Wander W, Weber H, Wellisch JP, Wenaus T, Williams DC, Wright D, Yamada T, Yoshida H, Zschiesche D. Geant4 - a simulation toolkit. Nuclear Instruments and Methods in Physics Research Section A. 2003; 506(3):250-303. http:// dx.doi.org/10.1016/S0168-9002(03)01368-8

Allison J, Amako K, Apostolakis J, Araujo H, Arce Dubois P, Asai M, Barrand G, Capra R, Chauvie S, Chytracek R, Cirrone GAP, Cooperman G, Cosmo G, Cuttone G, Daquino GG, Donszelmann M, Dressel M, Folger G, Foppiano F, Generowicz J, Grichine V, Guatelli S, Gumplinger P, Heikkinen A, Hrivnacova I, Howard A, Incerti S, Ivanchenko V, Johnson T, Jones F, Koi T, Kokoulin R, Kossov M, Kurashige H, Lara V, Larsson S, Lei F, Link O, Longo F, Maire M, Mantero A, Mascialino B, McLaren I, Mendez Lorenzo P, Minamimoto K, Murakami K, Nieminen P, Pandola L, Parlati S, Peralta L, Perl J, Pfeiffer A,. Pia MG, Ribon A, Rodrigues P, Russo G, Sadilov S, Santin G, Sasaki T, Smith D, Starkov N, Tanaka S, Tcherniaev E, Tomé B, Trindade A, Truscott P, Urban L, Verderi M, Walkden A, Wellisch P, Williams DC, Wright D, Yoshida H. Geant 4 developments and applications. IEEE Transactions on Nuclear Science. 2006; 53(1):270-8. http://dx.doi. org/10.1109/TNS.2006.869826

Almeida Junior AT. Caracterização da barita e do vidro cristal como atenuadores na blindagem das radiações $\mathrm{X}$ e Gama [tese]. Pernambuco: Universidade Federal de Pernambuco; 2005. 53 p. Disponível em: http://www. 
fundacentro.gov.br/dominios/ctn/teses_conteudo. asp? retorno $=153$.

Archer BR, Hornby JI, Bushong SC. Diagnostic X-ray shielding design based on an empirical model of photon attenuation. Health Physics. 1983; 44(5):507-17. http:// dx.doi.org/10.1097/00004032-198305000-00005

Brasil RB. Study and projects application to system shield from PET/CT Facilities [thesis]. São Paulo: Universidade de São Paulo; 2009. 90 p.

Brinkley B, Yester M, White S. Calculation of broad beam transmission factor for $511 \mathrm{keV}$. Photons using energy spectra measured in the presence of scatter. In: 2009 AAPM Annual Meeting Program. Medical Physics. 2009; 36(6):2449.

Cruzate J, Discacciatti A. Shielding of medical facilities. Shielding design considerations for PET-CT facilities. In: Congress of the International Radiation Protection Association: Proceedings of the 12th Congress of the International Radiation Protection Association; 2008; Buenos Aires, Argentina. Buenos Aires; 2008.

Demir D, Keles G. Radiation transmission of concrete including boron waste for 59.54 and $80.99 \mathrm{keV}$ gamma rays. Nuclear Instruments and Methods in Physics Research Section B. 2006; 245(2):501-4.

Elschot M, Wit TC, Jong HWAM. The influence of selfabsorption on PET and PET/CT shielding requirements. Medical Physics. 2010; 37(6):2999-3007. http://dx.doi. org/10.1118/1.3432618

Hoff G, Firmino SF, Souza WP. De. Influence of shielding composition on transmission curves determination for diagnostic radiology: A Monte Carlo study using the GEANT4 code. In: IEEE Nuclear Science Symposium Conference Record: Proceedings of the Nuclear Science Symposium Conference Record; 2009; Orlando. Orlando: IEEE; 2009. p. 540-3.

Hubbell JH, Seltzer SM. Tables of X-ray mass attenuation coefficients and mass energy-absorption coefficients from 1
$\mathrm{keV}$ to $20 \mathrm{MeV}$ for Elements $\mathrm{Z}=1$ to 92 and 48 additional substances of dosimetric interest. National Institute of Standard and Technology - NIST. Physical Reference Data; 1996. [cited 2012 May 05]. Available from: http://www. nist.gov/pml/data/xraycoef/index.cfm.

Hoff G, Pires de Souza W, Brasil RB, Costa PR. Simulating curves of transmission used on PET/CT applications, using Geant4 toolkit. In: IEEE Nuclear Science Symposium Conference Record: Proceedings of the Nuclear Science Symposium Conference Record; 2010; Knoxvile. Knoxvile: IEEE; 2010. p. 1199-202.

International Commission on Radiation Units and Measurements - ICRU. Report 44 - Tissue substitutes in radiation dosimetry and measurements. Maryland; 1989. p. 189.

Madsen MT, Anderson JA, Halama JR, Kleck J, Simpkin D, Votaw JR, Wendt III RE, Williams LE, Yester MV. AAPM Task Group 108: PET and PET/CT shielding requirements. Medical Physics. 2006. 33(1):4-15. http:// dx.doi.org/10.1118/1.2135911

National Council on Radiation Protection and Measurements - NCRP. Report 147 - Structural shielding design for medical X-ray imaging facilities. NCRP; 2005. p. 194.

Simpkin DJ. Shielding requirements for constant-potential diagnostic X-ray beams determined by a Monte Carlo calculation. Health Physics. 1989; 56(2):151-64. http:// dx.doi.org/10.1097/00004032-198902000-00002

Simpkin DJ. Transmission data for shielding diagnostic X-ray facilities. Health Physics. 1995; 68(5):704-9. http:// dx.doi.org/10.1097/00004032-199505000-00011

Singh K, Singh H, Sharma V, Nathuram R, Khanna A, Kumar R, Bhatti SS, Sahota HS. Gamma-ray attenuation coefficients in bismuth borate glasses. Nuclear Instruments and Methods in Physics Research Section B. 2002; 194(1):1-6. http:// dx.doi.org/10.1016/S0168-583X(02)00498-6

\footnotetext{
Authors

Gabriela Hoff

Grupo de Experimentação e Simulação Computacional em Física Médica,

Pontifícia Universidade Católica do Rio Grande do Sul - PUCRS, Porto Alegre, RS, Brasil

Paulo Roberto Costa*

Laboratório de Dosimetria das Radiações e Física Médica

Departamento de Física Nuclear, Instituto de Física, Universidade de São Paulo - USP, São Paulo, SP, Brasil.
} 